\title{
Quantitative Determination of Composition of Particle Type by Morphology of Nanoparticles in Diesel Exhaust and Roadside Atmosphere
}

\author{
Yuji Fujitani ${ }^{1 *}$, Tetsuo Sakamoto ${ }^{2}$ and Kentaro Misawa ${ }^{3}$ \\ ${ }^{1}$ Research Center for Environmental Risk, National Institute for Environmental Studies, Tsukuba, Japan \\ ${ }^{2}$ Kogakuin University, 2665-1 Nakanocho, Hachioji, Tokyo 192-0015, Japan \\ ${ }^{3}$ Tokyo Institute of Technology, 4259 Nagatsuta-cho, Midori-ku, Yokohama, Kanagawa 226-8503, Japan
}

\begin{abstract}
Particles were collected in diluted diesel exhaust under high-idle and high-torque operating conditions and from the air above roadsides. We analyzed particle morphology of particles that were $30,50,70$, and 100 nm in electrical mobility diameter $\left(D_{m}\right)$ by transmission electron microscope. We classified ten types of particles based on particle morphology and found that diesel exhaust particles (DEPs) of $D_{m}=70$ and $100 \mathrm{~nm}$ composed at least $14 \%$ and $58 \%$, respectively, of atmospheric particles at each particle size. From the two-dimensional transmission electron microscope images, we derived three-dimensional morphological properties of the agglomerates and found that the numbers and diameters of the primary particles in the agglomerates were similar to those of DEPs at a given $D_{m}$. However, the active surface areas of the roadside atmospheric particles were systematically smaller than those of DEPs.
\end{abstract}

Keywords: Diesel exhaust particle; Agglomerate; Morphology; Transmission electron microscope; Roadside atmosphere; Nanoparticle; Ultrafine particle; Active surface area

\section{Introduction}

Atmospheric quality standards regulate particulate matter with diameters of $2.5 \mu \mathrm{m}$ and smaller $\left(\mathrm{PM}_{2.5}\right)$ based on their mass concentration. Nanoparticles, that is, particles with a diameter of less than $50 \mathrm{~nm}$ [1], in diesel exhaust are included in, but contribute minimally to $\mathrm{PM}_{25}$. Despite their minor contribution to $\mathrm{PM}_{2.5}$, nanoparticles have drawn increasing attention because of their toxicity and associated health risks [2] as a result of their increased deposition, in terms of number of particles, compared to larger particles. For example, in urban environments the concentration of nanoparticles in the atmosphere is considerably higher than that of larger particles [3], with particles $10-20 \mathrm{~nm}$ in diameter contributing to the highest alveoli deposition [4]. Particles deposited in human alveoli are hypothesized to penetrate the cell membrane and enter the bloodstream before being transported to other organs [5,6]; this is especially applicable to insoluble particles. The degree of adverse health effects associated with insoluble nanoparticles may depend on their chemical composition and dose in terms of number and surface area of the particles. The toxicity of inhaled particles is also related to particle morphology, such as physical size and particle length; for example, fiber length or aspect ratio (length/ width) is an important toxicity parameter of fiber particles [7]. Inhaled fiber particles may enter deep into the lungs, regardless of their fiber length, and are easily deposited by the intersections that are specific for airborne particles with a fiber-like structure [8]. Morphologies of agglomerates are also important because surface area increases as more particles agglomerate. In addition, the number of primary particles in an agglomerate is important; when agglomerates are deposited at the alveoli and dissolve, the disagglomerate particles are smaller than the original particle size of agglomerates, and these smaller particles are more easily transferred to the cell membrane, resulting in a greater number of primary particles being transported to other organs.

In this study, we collected diesel exhaust particles generated in our laboratory and roadside atmospheric particles and examined particle morphology using a transmission electron microscope (TEM). We classified particle type based on morphology and collected particles according to particle size based on electrical mobility because the depositional area after inhalation is a function of the particle aerodynamic diameter or diffusive equivalent diameter [4], not the physical particle size. We conclude by discussing particle morphology in relation to particle toxicity.

\section{Materials and Methods}

\section{Aerosol sampling}

An $8 \mathrm{~L}$ diesel engine (meeting 1997 emission regulations and not fitted with after-treatment devices), located in the Nanoparticle Health Effect Laboratory, National Institute for Environmental Studies $[9,10]$, was used for sampling diesel exhaust particles. The engine was operated at a steady state of $2000 \mathrm{rpm}$ and $0 \mathrm{Nm}$ (high idle) and 1000 $\mathrm{rpm}$ and $300 \mathrm{Nm}$ (high load). Exhausts were introduced to a primary dilution tunnel and diluted with particle-free clean air at a flow rate of $100 \mathrm{~m}^{3} \mathrm{~min}^{-1}$ to obtain a dilution ratio of 16 times (high idle) and 28 times (high load). The sample air was induced into sampling system from the primary dilution tunnel by conductive silicon tubing (i.d. 4.8 $\mathrm{mm}$, length $0.45 \mathrm{~m}$ ). Sampling duration for each collection was 10-30 minutes. Sulfur free fuel (about 6 ppm; JIS No. 2 light oil, available and generally used in Japan) and lubricant oil (E Pro Extra 10W-30, Hino Motors, Tokyo, Japan) were used. We collected one sample for each particle size and each engine operating condition, and each sample consist four TEM grids.

For roadside particles, sampling was conducted around a traffic intersection in Kawasaki City, Kanagawa Prefecture, Japan, where a main highway, Industrial Road, crosses another road. Kawasaki City has a population of about 1.4 million, and its air is considered to be heavily polluted. Size-resolved particle number concentration, suspended particulate matter, gaseous pollutants (e.g., NOx), and meteorological parameters have been measured continuously at a

*Corresponding author: Yuji Fujitani, Research Center for Environmental Risk National Institute for Environmental Studies, 16-2 Onogawa, Tsukuba 305-8506 Japan, Tel: +81-29-850-2014; E-mail: fujitani.yuji@nies.go.jp

Received August 18, 2012; Accepted September 14, 2012; Published Septembe 24, 2012

Citation: Fujitani Y, Sakamoto T, Misawa K (2012) Quantitative Determination of Composition of Particle Type by Morphology of Nanoparticles in Diesel Exhaust and Roadside Atmosphere. J Civil Environ Eng S1:002. doi:10.4172/2165-784X. S1-002

Copyright: (C) 2012 Fujitani Y, et al. This is an open-access article distributed under the terms of the Creative Commons Attribution License, which permits unrestricted use, distribution, and reproduction in any medium, provided the original author and source are credited. 
long-term monitoring site near the intersection since 2003 [11-13]. Industrial Road is $30 \mathrm{~m}$ wide (seven traffic lanes), and the Metropolitan Expressway is elevated above it. The average traffic volume during the weekday at this intersection is approximately 52,000 vehicles, about $25 \%$ of which are heavy-duty diesel vehicles. For this study, particle sampling at the intersection was conducted for short periods during winter (23-25 January 2012). All samplings were conducted on weekdays from 600 to 1000 and from 1500 to 1900 local time. The sample air was induced into sampling system in the monitoring site by cupper tubing (inner diameter $4 \mathrm{~mm}$, length $2.9 \mathrm{~m}$ ). Sampling duration for each environmental sample was 1 hour period. We collected four samples during the sampling period for each particle size and each sample consist four TEM grids.

In the laboratory experiment, for high-idle operating conditions, the modal diameter of the diesel exhaust particles was $20 \mathrm{~nm}$ and the EC/TC was 0.24, with few soot particles. Detailed chemical speciation of the diesel exhaust particles was conducted in a previous study [14]. In contrast, under high-load conditions, the modal diameter was 50-60 $\mathrm{nm}$ and the EC/TC was 0.85 ; typical soot particles were dominant in bulk samples. The roadside atmospheric particles had an average modal diameter of $24.7 \pm 16 \mathrm{~nm}$ ( \pm standard deviation [SD]) and an average total particle number concentration of $4.3 \pm 3.2 \times 10^{4} \mathrm{~cm}^{-3}$ during January 2012 at the long-term monitoring site. The ratio of elemental carbon (EC) to total carbon (TC) was 0.57 .

\section{Instrumentation}

Figure 1 shows a schematic diagram of the sampling system. The size-resolved sample was obtained by using a differential mobility analyzer (DMA; SIBATA Scientific Technology, Soka, Saitama, Japan) and an electrical precipitator (SIBATA). Particles with electrical mobility diameters $\left(D_{m}\right)$ of $30,50,70$, and $100 \mathrm{~nm}$ were classified by the DMA with a ratio of sheath to sample flow rate of 10:1. Sample flow rates were set at $2 \mathrm{~L} \mathrm{~min}{ }^{-1}$ and $10 \mathrm{~L} \mathrm{~min}^{-1}$ for laboratory sampling and atmospheric sampling, respectively. The size distribution was measured with a scanning mobility particle sizer (SMPS; model 3936; TSI, Shoreview, MN, USA) after a pass through the DMA, and the $\mathrm{D}_{\mathrm{m}}$ described above were determined by changing the voltages of the DMA. Particle size distributions before passing through the DMA were also measured with another SMPS (model 3034; TSI). An electrical precipitator was operated at $9 \mathrm{kV}$, and charged particles were collected evenly on 200-mesh collodion membrane-coated copper grids (Nisshin EM, Tokyo, Japan) after a pass through the DMA. Particle morphology was observed with a TEM (JEM-2010; JEOL, Akishima, Japan). Particle images were taken at a magnification of 200,000 for a single particle per image. Images were processed with Adobe Photoshop (ver. 12.04). For agglomerates, surface area and number of primary particles were derived using a published method [15]. Each sample was analyzed from 20-50 images.

\section{Results and Discussion}

\section{Representations of sample and DMA size selection}

For the roadside atmospheric sample, we analyzed collections from 600 to 1000 on 25 January, 2012. We checked the representation of the collections by using SMPS data from the long-term monitoring site. The modal diameter and total particle number concentration were 22.4 $\pm 7 \mathrm{~nm}$ and $9.1 \pm 4.1 \times 10^{4} \mathrm{~cm}^{-3}$, respectively, during the above period (Figure 2A), and these values are comparable to 1-month-average data from the long-term monitoring site. Therefore, we consider the sampling period to be typical of conditions in January at this intersection.
The size selection of the DMA is based on the electrical mobility of charged particles (Figure $2 \mathrm{~B}$ ). $\mathrm{D}_{\mathrm{m}}$ is the defined particle diameter that has the same electrical mobility as a singly charged spherical particle. Therefore, the same electrical mobility of particles is selected regardless of whether this is singly charged targeted-size particles or multiply charged larger particles. For example, the mobility of a singly charged $100 \mathrm{~nm}$ particle is the same for a doubly charged $152 \mathrm{~nm}$ particle (Table 1). We estimate the contribution of the particle number of doubly charged larger particles to the particle number of singly charged targeted-size particles, which determined from the charged probability of each particle size and size distributions measured with a SMPS before entering the DMA (Table 1). The smaller the targeted particle size, the smaller the contribution of particle number from doubly charged larger particles because the probability of occurrence of a doubly charged particle is less for smaller targeted particles than

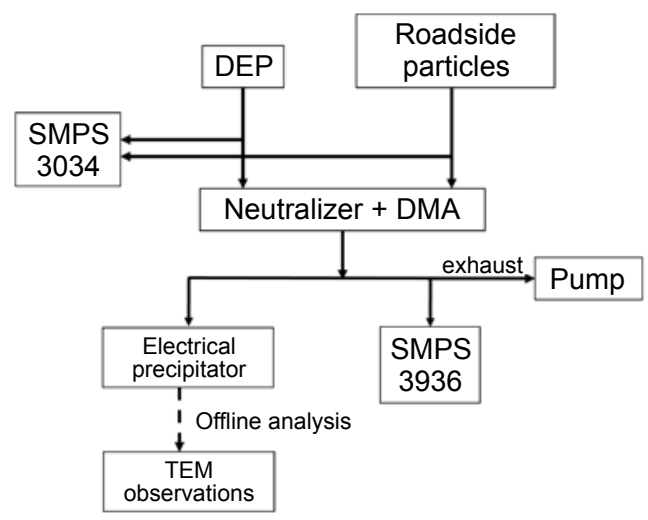

Figure 1: Schematic diagram of the sampling system. DEP, diesel exhaust particle; SMPS, scanning mobility particle sizer; DMA, differential mobility analyzer; TEM, transmission electron microscope.

A) Total

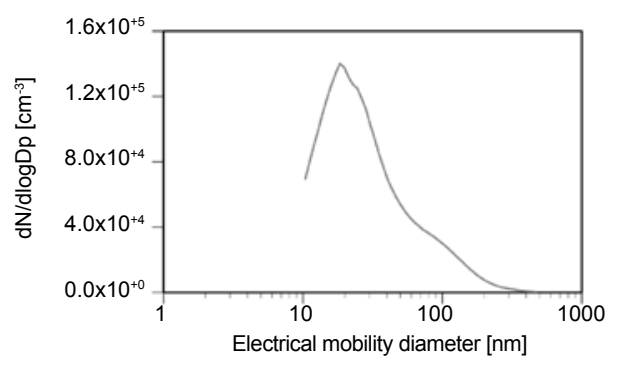

B) After DMA

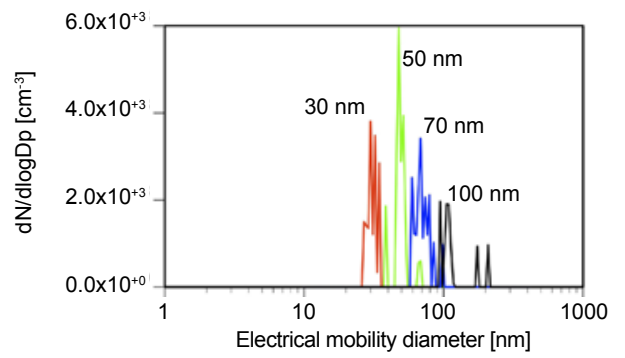

Figure 2: (A) Size distribution of roadside atmospheric particles measured with a scanning mobility particle sizer (SMPS) model 3034 in 25 January 2012 at Kawasaki, Japan; (B) size distribution of roadside atmospheric particles measured with an SMPS model 3936 after classification by a differential mobility analyzer. 
Citation: Fujitani Y, Sakamoto T, Misawa K (2012) Quantitative Determination of Composition of Particle Type by Morphology of Nanoparticles in Diesel Exhaust and Roadside Atmosphere. J Civil Environ Eng S1:002. doi:10.4172/2165-784X.S1-002

Page 3 of 6

for larger targeted particles. Consequently, we assumed that the contribution of doubly charged larger particles was less than $21 \%$ in our sample (Table 1).

A previous study showed that projected area equivalent diameters $\left(\mathrm{D}_{\text {eq }}\right)$ of $\mathrm{TiO}_{2}$ and $\mathrm{Si}$ agglomerates are nearly equal to the $\mathrm{D}_{\mathrm{m}}$ of particles with $\mathrm{D}_{\mathrm{m}}$ up to $400 \mathrm{~nm}$ [16]. Diesel agglomerates in the $\mathrm{D}_{\mathrm{m}} 50-220 \mathrm{~nm}$ range have also been shown to have a $D_{\text {eq }}$ that is approximately the same as the $\mathrm{D}_{\mathrm{m}}$ [17]. We measured the projected area of particles by image analysis and calculated the $\mathrm{D}_{\mathrm{eq}}$ from the projected area (Figure 3 ); we then compared the $D_{\text {eq }}$ to the $\mathrm{D}_{\mathrm{m}}$ measured by an SMPS. Figure 4 shows a comparison for each type of particle between $\mathrm{D}_{\mathrm{m}}$ measured by an SMPS and $\mathrm{D}_{\mathrm{eq}}$ determined by TEM observation after classification by the DMA. $D_{m}$ and $D_{e q}$ agreed well, particularly for the roadside atmospheric sample. Our results for $\mathrm{D}_{\mathrm{m}}$ of $30-100 \mathrm{~nm}$ for the roadside atmospheric sample are comparable with results from previous studies $[16,17]$. The $\mathrm{D}_{\text {eq }}$ of DEPs for high-load was slightly larger than the $\mathrm{D}_{\mathrm{eq}}$ of the other types of particles (Figure 4); this may be due to the high contribution of doubly charged larger particles (Table 1).

\section{Particle morphology}

We classified images based on particle morphology as agglomerate, irregularly shaped, bar-like, and round; in addition, particles were classified based on electron opacity and electron transparency as a qualitative description of the different materials that compose particles as observed by TEM $[18,19]$ and on the partial evaporation of particles during TEM observation [20]. Figures 5 and 6 show images of typical DEPs and roadside atmospheric particles, respectively. Only agglomerate-opaque particles were found in the high-load of DEPs (Figure 7A); these may be soot particles, which consist mainly of EC and have a surface covered with organic carbon (OC). Only agglomerateopaque particles were found under high-idle conditions for particles with $\mathrm{D}_{\mathrm{m}}$ of 70 and $100 \mathrm{~nm}$, while irregularly shaped particles were also observed for particles with $\mathrm{D}_{\mathrm{m}}$ of 30 and $50 \mathrm{~nm}$. For particles with $\mathrm{D}_{\mathrm{m}}$ of $30 \mathrm{~nm}$, transparent and partially evaporated particles were also found, and these may consist mainly of OC. The electron beam caused a partial evaporation of the volatile material [20] and evaporation was observed at the lower left in the particle (Fig. 5D). Our results are consistent with the chemical analysis of DEPs: (1) the EC/TC ratio of high-torque conditions is higher than that of high-idle conditions, and the contribution of agglomerate-opaque particles to measured particles is also dominant under high-torque conditions compared to high-idle conditions; (2) DEPs smaller than $30 \mathrm{~nm}$ in diameter under high-idle conditions are generally composed of material that evaporates easily [21], and OC constitutes the major part (79-80\%) of nanoparticles (diameter 10-32 nm) in diluted diesel exhaust [14]
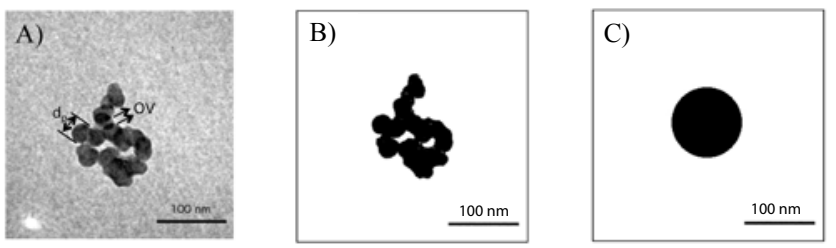

Figure 3: Image processing of electrical mobility diameter $\left(D_{m}\right)=100 \mathrm{~nm}$ for diesel exhaust particles under high-idle conditions. (A) Original image and diameter of primary particle $\left(d_{p}\right)$ and overlap segment (OV); $(B)$ shade image from original image. Projected area $\left(A_{a}\right)$ was determined from this image; $(C)$ image of circle that have projected area equivalent particle diameter $\left(D_{e q}\right)$ which corresponds to original image of particle. Scale bars provide a size reference. under the same engine and engine operating conditions (high idle) used in our laboratory. From size-resolved chemical analysis, Fushimi et al. [14] also suggested that both EC-rich and OC-rich nanoparticles are generated under high-idle operating conditions. Our data also support this hypothesis that agglomerate-opaque particles are present in particles with $\mathrm{D}_{\mathrm{m}}=30 \mathrm{~nm}$ and that these are likely to be soot particles.

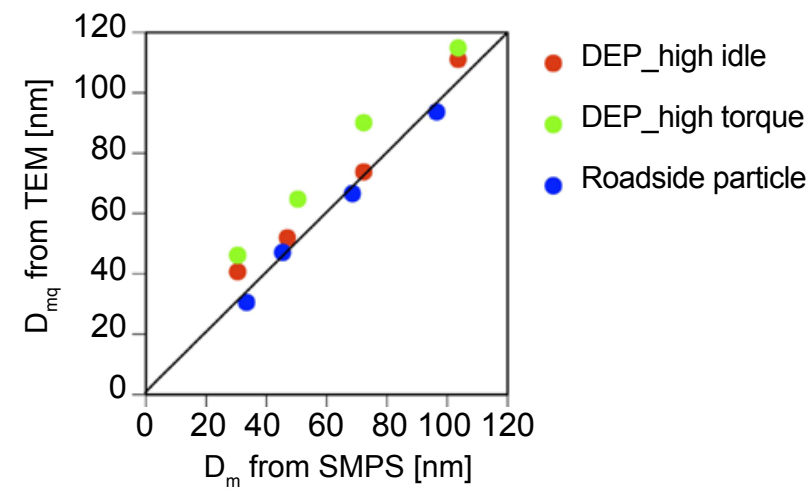

Figure 4: Comparison between particle electrical mobility diameter (D determined by a scanning mobility particle sizer (SMPS) and projected area equivalent diameter $\left(D_{\text {eq }}\right)$ determined by transmission electron microscope (TEM) observation after classification by a differential mobility analyzer for each type of particle. DEP, diesel exhaust particle.
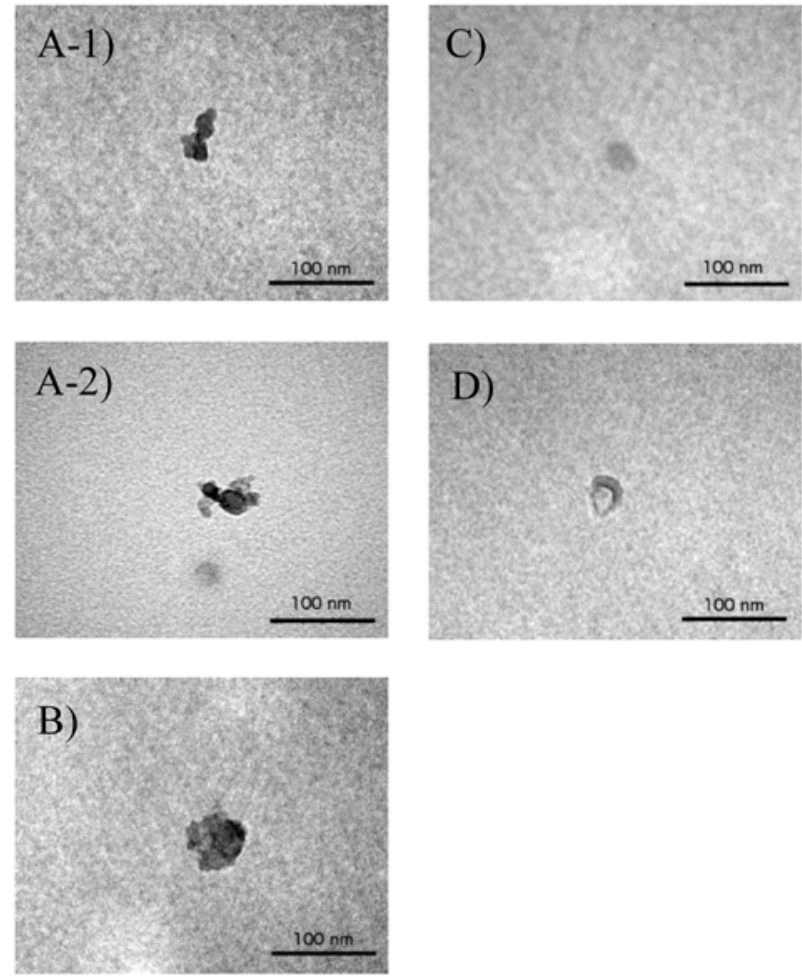

Figure 5: Typical diesel exhaust particle with electrical mobility diameter $\left(D_{m}\right)=30 \mathrm{~nm}$. (A-1) Agglomerate electron-opaque particle (high idle); (A-2) agglomerate electron-opaque particle (high torque); (B) irregularly shaped electron-opaque particle (high idle); (C) irregularly shaped electron-transparent particle (high idle); (D) irregularly shaped partially evaporated particle (high idle). Scale bars provide a size reference. 
For the roadside atmospheric sample, agglomerates were found at all particle sizes, and their source may be emissions from diesel cars (Figure 7B). Bar-like particles were also observed at all particle sizes, but no such particles were observed in DEPs, indicating that bar-like particles were derived from other sources. Zn-rich metallic oxide has been detected from polygonal particles [22], which are similar to barlike particles; and metallic oxide particles are often observed in urban and industrial sites [22]. The contribution of agglomerate-opaque particles in the roadside atmospheric sample was highest in particles with $\mathrm{D}_{\mathrm{m}}=100 \mathrm{~nm}$ and lowest in particles with $\mathrm{D}_{\mathrm{m}}=30 \mathrm{~nm}$, which is consistent with DEPs under high-idle conditions (Figure 7A). For $\mathrm{D}_{\mathrm{m}}=70$ and $100 \mathrm{~nm}$, only agglomerate-opaque particles were measured in both DEPs and agglomerate-opaque particles contributed $14 \%$ and $58 \%$, respectively, to the composition of the roadside atmospheric sample. By assuming agglomerate-opaque particles are generated solely from diesel exhaust in the environment, these values are suggested to be minimum values for the contribution of DEPs in roadside particles. For particles with $\mathrm{D}_{\mathrm{m}}=30 \mathrm{~nm}$, irregularly shaped-opaque, transparent, and partially evaporated particles were also observed in roadside atmospheric sample and they are also in DEPs under high-idle conditions. Our data indicate that irregularly shaped transparent and irregularly shaped partially evaporated particles were more abundant in particles with $\mathrm{D}_{\mathrm{m}}=30 \mathrm{~nm}$ than in larger particles in both DEP under high-idle conditions and the roadside atmosphere sample.

\section{Properties of agglomerates}

We derived three-dimensional (3-D) morphological properties of agglomerates from the two-dimensional (2-D) image [15]. An example of image processing for particles with $\mathrm{D}_{\mathrm{m}}=100 \mathrm{~nm}$ under highidle operating conditions is shown in Figure 3. The primary particle diameter $\left(d_{p}\right)$ and overlap segment $(O V)$ were obtained from the original image (Figure $3 \mathrm{~A}$ ) and 2-D overlap coefficient $\left(\mathrm{C}_{\mathrm{OV} \text {, projected }}=\mathrm{OV} /\right.$ $\left.d_{p}\right)$ was determined. The original images were then converted to shade images (Figure $3 \mathrm{~B}$ ), and the projected area of an agglomerate $\left(\mathrm{A}_{\mathrm{a}}\right)$ was determined. The number of primary particles $(\mathrm{N})$ in the agglomerate was derived using the $3-\mathrm{D} \mathrm{C}_{\mathrm{OV}}$ (derived from $\mathrm{C}_{\mathrm{OV} \text {, projected }}$ ), $\mathrm{A}_{\mathrm{a}}$, and crosssectional area of a primary particle $\left(=\pi \mathrm{d}_{\mathrm{p}}{ }^{2} / 4\right)$. The 3-D active surface area of the agglomerate was derived using $\mathrm{N}, 3-\mathrm{D} \mathrm{C}_{\mathrm{OV}}$, and 3-D surface area of primary particles $\left(=\pi \mathrm{Nd}_{\mathrm{p}}{ }^{2}\right)$. Table 2 shows the properties of an agglomerate for each size of the three particle types used in this study. TEM observations of these particles indicated that $\mathrm{N}$ and $\mathrm{d}_{\mathrm{p}}$ increased as $\mathrm{D}_{\mathrm{m}}$ increased. The $\mathrm{d}_{\mathrm{p}}$ ranged from 17.2 to $29.8 \mathrm{~nm}$ for DEPs, which is consistent with fractal-like diesel exhaust agglomerates having primary particles $15-30 \mathrm{~nm}$ in diameter $[23,24]$. A comparison of the $d_{p}$ between high-idle and high-load conditions at a given $D_{m}$ shows that $\mathrm{d}_{\mathrm{p}}^{\mathrm{p}}$ was larger under high-load conditions by a factor of 1.1 and values were independent of $\mathrm{D}_{\mathrm{m}}$. The concentration of total hydrocarbon in the exhaust was also higher under high-load conditions compared to high-idle conditions by 1.16 times, and we assume that vaporized materials condensed on the primary particles during cooling before agglomeration and that this process of condensation was more advanced under high-load conditions. Roadside atmospheric particles are a mix of emitted particles from various engine types and engine operating conditions, and these particles would have a longer residence time than DEPs collected in our laboratory. However, it is interesting that the $\mathrm{d}_{\mathrm{p}}$ of roadside atmospheric particles fell within the range of operating conditions of the single 8-L engine type used in our laboratory. Our results suggest that the emission process of diesel agglomerates from tailpipe to roadside atmosphere did not alter the properties of the primary particles in roadside agglomerates.

Active surface areas of agglomerates were larger than those of spherical particles at a given $\mathrm{D}_{\mathrm{m}}$. Active surface area is the surface on which momentum, energy, and mass are transferred from the gas to the particle [25]. If toxic substances adsorb on the particle, the burden of condensed material increases because the active particle surface is larger. Consequently, the larger active surface area of an agglomerate would be more toxic than that of a spherical particle at a given $\mathrm{D}_{\mathrm{m}}$ Especially for DEPs, the ratio of active surface area of an agglomerate to a spherical particle generally increases as $\mathrm{D}_{\mathrm{m}}$ decreases for both engine

\begin{tabular}{|c|c|c|c|}
\hline & \multicolumn{2}{|c|}{$\begin{array}{c}\text { Contribution of the number of doubly charged particles to that of singly } \\
\text { chareged particles }\end{array}$} & \multicolumn{2}{c}{\begin{tabular}{c} 
num \\
\hline $\begin{array}{c}\text { Target (singly charged) } \\
\text { diameter [nm] }\end{array}$
\end{tabular}} & $\begin{array}{c}\text { Particle size of doubly charged particles with the } \\
\text { same mobility as target [nm] }\end{array}$ & High idle (DEP) & High load (DEP) & Roadside atmospheric particle \\
\hline 30 & 46 & 0.01 & 0.07 \\
\hline 50 & 73 & 0.06 & 0.12 \\
\hline 70 & 104 & 0.08 & 0.15 \\
\hline 100 & 152 & 0.09 & 0.07 \\
\hline
\end{tabular}

DEP, diesel exhaust particle

Table 1: Targeted particle size of a singly charged particle and the size of a doubly charged larger particle with the same mobility. Estimation of the contribution of particle number of doubly charged larger particles to the number of singly charged targeted-size particles from size distributions measured with a scanning mobility particle sizer before entering a differential mobility analyzer and probability of charges that depend on particle size.

\begin{tabular}{|c|c|c|c|c|c|c|c|c|c|c|c|c|}
\hline \multirow[b]{2}{*}{ Mobility diameter $\left(D_{m}\right)[n m]$} & \multicolumn{4}{|c|}{ High ilde (DEP) } & \multicolumn{4}{|c|}{ High load (DEP) } & \multicolumn{4}{|c|}{ Roadside atmospheric particles } \\
\hline & 30 & 50 & 70 & 100 & 30 & 50 & 70 & 100 & 30 & 50 & 70 & 100 \\
\hline $\begin{array}{l}\text { Primary particle diameter }\left(\mathrm{d}_{\mathrm{p}}\right) \\
{[\mathrm{nm}]}\end{array}$ & $17.2 \pm 3.6$ & $19.8 \pm 4.4$ & $22.0 \pm 4.6$ & $26.8 \pm 7.4$ & $18.8 \pm 4.9$ & $23.1 \pm 4.0$ & $24.6 \pm 4.2$ & $29.8 \pm 6.0$ & & $22.6 \pm 4.8$ & $23.5 \pm 3.9$ & $26.9 \pm 8.6$ \\
\hline $\begin{array}{l}\text { Number of primary particles in } \\
\text { single agglomerate }(\mathrm{N})\end{array}$ & $9.1 \pm 3.4$ & $11.7 \pm 6.7$ & $\begin{array}{c}21.5 \pm \\
10.7\end{array}$ & $\begin{array}{c}39.8 \pm \\
20.5\end{array}$ & $11.3 \pm 5.9$ & $15.6 \pm 9.2$ & $25.5 \pm 8.9$ & $\begin{array}{c}31.9 \pm \\
13.4\end{array}$ & & $8.9 \pm 2.9$ & $16.0 \pm 5.1$ & $\begin{array}{c}29.2 \pm \\
10.6\end{array}$ \\
\hline $\begin{array}{l}\text { Active surface area of single } \\
\text { agglomerate }\left[\times 10^{4} \mathrm{~nm}^{2}\right]\end{array}$ & $\begin{array}{l}0.72 \pm \\
0.27\end{array}$ & $\begin{array}{l}1.19 \pm \\
0.67\end{array}$ & $\begin{array}{c}2.22 \pm \\
1.07\end{array}$ & $\begin{array}{c}4.80 \pm \\
2.41\end{array}$ & $\begin{array}{c}0.78 \pm \\
0.38\end{array}$ & $\begin{array}{l}1.66 \pm \\
0.95\end{array}$ & $\begin{array}{l}3.31 \pm \\
1.13\end{array}$ & $\begin{array}{l}5.15 \pm \\
2.11\end{array}$ & & $\begin{array}{l}0.83 \pm \\
0.25\end{array}$ & $\begin{array}{l}1.75 \pm \\
0.54\end{array}$ & $\begin{array}{c}3.52 \pm \\
1.24\end{array}$ \\
\hline $\begin{array}{c}\text { Ratio of active surface area of } \\
\text { an agglomerate to a spherical } \\
\text { particle }\end{array}$ & 2.55 & 1.52 & 1.44 & 1.53 & 2.75 & 2.12 & 2.15 & 1.64 & & 1.06 & 1.14 & 1.12 \\
\hline
\end{tabular}

DEP, diesel exhaust particle

Properties of $D_{m}=30 \mathrm{~nm}$ for roadside atmospheric particles are not included due to the small number of agglomerates

Table 2: Physical properties of agglomerates. 

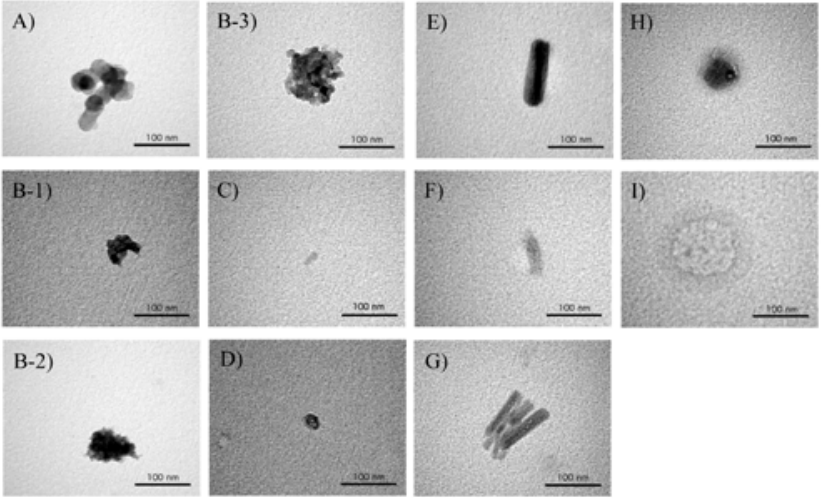

G)

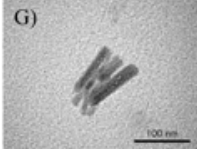

Figure 6: Typical particles in roadside atmosphere. (A) Agglomerate electronopaque particle $\left(D_{m}=100 \mathrm{~nm}\right) ;(B-1)$ irregularly shaped electron-opaque particle $(D=50 \mathrm{~nm})$; $(B-2)$ irregularly shaped electron-opaque particle $(D=$ $70 \mathrm{~nm}) ;(B-3)$ irregularly shaped electron-opaque particle $\left(D_{m}=100 \mathrm{~nm}\right) ;(C)$ irregularly shaped electron-transparent particle $\left(D_{m}=30 \mathrm{~nm}\right) ;(D)$ irregularly shaped partially evaporated particle $(D=30 \mathrm{~nm})$; $(E)$ bar-like electronopaque particle $\left(D_{m}=100 \mathrm{~nm}\right) ;(F)$ bar-like electron-transparent particle $\left(D_{m}=\right.$ $50 \mathrm{~nm}) ;(\mathrm{G})$ bar-like, agglomerate, electron-opaque particle $\left(D_{m}=100 \mathrm{~nm}\right) ;(H)$ round electron-opaque particle $\left(D_{m}=70 \mathrm{~nm}\right)$; (I) round electron-transparent particle $\left(D_{m}=100 \mathrm{~nm}\right)$. Scale bars provide a size reference.

A)

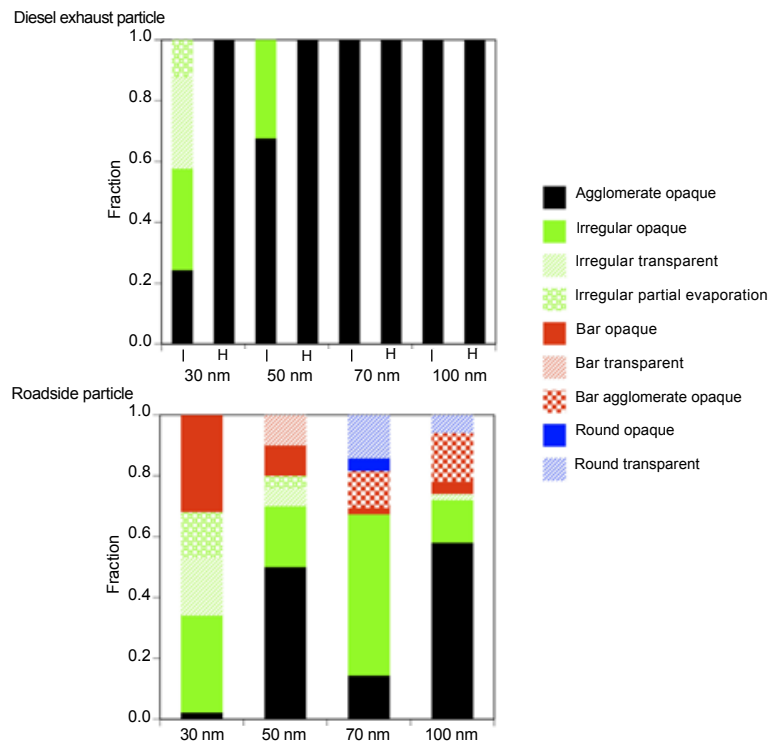

Figure 7: Number of fractions of typical particles in (A) diesel exhaust particles and $(B)$ roadside atmospheric particles for each $D_{m}$. I and $\mathrm{H}$ are high-idle and high-load engine operating conditions, respectively.

operating conditions (Table 2). Ultrafine and fine $\mathrm{TiO}_{2}$ show that at the same mass dose, ultrafine particles have a significantly greater inflammatory potential than fine particles [26]. Therefore, our results suggest that DEPs are more toxic in smaller particles than in larger particles, at a given mass or number dose of particles and a particle surface covered with a toxic substance. The ratio of active surface area of an agglomerate to a spherical particle for the roadside atmospheric particles was systematically lower than those of DEPs at a given $\mathrm{D}_{\mathrm{m}}$, and the size dependency of the ratios was weak. Agglomerates from the roadside atmosphere were more compact than DEPs collected in our laboratory at a given $\mathrm{D}_{\mathrm{m}}$, suggesting that the emission process of diesel agglomerates from tailpipe to roadside atmosphere altered the morphology of roadside agglomerates, most probably by condensation of volatile materials.

The number of primary particles $(\mathrm{N})$ was similar for all particles at a given $\mathrm{D}_{\mathrm{m}}$. If the number of particles were to increase at a given $\mathrm{D}_{\mathrm{m}}$ the dose in terms of particle number would increase. If agglomerates were to be deposited in the lungs, it is possible that these agglomerates would disagglomerate in the alveolar lining. Although, a previous study found that lung surfactant does not promote the disaggregation of $\mathrm{TiO}_{2}$ agglomerates and aggregates [27], diesel exhaust may be hydrophobic due to its organic surface cover, because lung surfactant is amphiphilic, the possibility that agglomerates become disagglomerated in alveolar fluid cannot be ruled out. If the agglomerates were to disagglomerate into nanometer-size particles, they could then behave as nanoparticles (e.g., penetrating the cell membranes and entering blood vessels to be transported by the blood to other organs). The fraction of the agglomerates in the roadside atmosphere was only $2 \%$ at $\mathrm{D}_{\mathrm{m}}=30$ $\mathrm{nm}$ (Figure 7); however, if an agglomerate dissolves in the alveoli, then 9-11 particles with particle diameter of 17-19 $\mathrm{nm}$ disperse in the alveoli (assuming that the roadside atmospheric particle has the same properties as a DEP at $\mathrm{D}_{\mathrm{m}}=30 \mathrm{~nm}$ ). Therefore, an agglomerate would generate ten times the number of nanoparticles, suggesting that agglomerates largely contribute to a deposited dose in terms of particle number in alveoli in spite of composing a low fraction of an agglomerate.

\section{Conclusions}

We used TEM to observe the morphology of particles that were collected along a roadside and in diesel exhausts under high-idle and high-torque operating conditions. For $\mathrm{D}_{\mathrm{m}}=30 \mathrm{~nm}$ under high-idle operating conditions, transparent or partially evaporated particles as well as agglomerates were observed, and these results are consistent with the results of previous size-resolved chemical analysis. Primary particle diameters and number of primary particles in roadside atmospheric agglomerates were similar to those of DEPs at a given $\mathrm{D}_{\mathrm{m}}$, while active surface area was less. Our results suggest that the emissions process from tailpipe to roadside atmosphere did not alter the properties of primary particles in roadside atmospheric agglomerates but did alter the morphology of roadside agglomerates as a result of condensation of volatile materials. Our study also showed TEM is a powerful tool to analyze properties of agglomerates to predict toxicity of agglomerates after deposition in the body.

\section{Acknowledgements}

We thank Dr. S. Hirano (National Institute for Environmental Studies [NIES]) and Dr. A. Furuyama (NIES) for useful discussions. We thank S. Kinoshita (NIES), T. Fujii (Horiba Techno Service), M. Ihara (NIES), and Y. Sugaya (NIES) for their excellent technical assistance and data analysis. This research was supported by the Environment Research and Technology Development Fund (C-1002) of the Ministry of the Environment, Japan.

\section{References}

1. Kittelson DB (1998) Engines and nanoparticles: A review. J Aero Sci 29: 575588 .

2. Oberdorster G, Oberdorster E, Oberdorster J (2005) Nanotoxicology: An emerging discipline evolving from studies of ultrafine particles. Environ Health Perspect 113: 823-839.

3. Kumar P, Robins A, Vardoulakis S, Britter R (2010) A review of the characteristics of nanoparticles in the urban atmosphere and the prospects for developing regulatory controls. Atmos Env 44: 5035-5052.

4. ICRP (1994) Human respiratory tract model for radiological protection. Pergamon Press, Oxford

5. Takenaka S, Karg E, Roth C, Schulz H, Ziesenis A, et al. (2001) Pulmonary and systemic distribution of inhaled ultrafine silver particles in rats. Environ Health Persp 109: 547-551. 
Citation: Fujitani Y, Sakamoto T, Misawa K (2012) Quantitative Determination of Composition of Particle Type by Morphology of Nanoparticles in Diesel Exhaust and Roadside Atmosphere. J Civil Environ Eng S1:002. doi:10.4172/2165-784X.S1-002

6. Oberdorster G, Sharp Z, Atudorei V, Elder A, Gelein R, et al. (2002) Extrapulmonary translocation of ultrafine carbon particles following whole-body inhalation exposure of rats. J Toxicol Env Heal A 65: 1531-1543.

7. Stanton MF, Layard M, Tegeris A, Miller E, May M, et al. (1981) Relation of Particle Dimension to Carcinogenicity in Amphibole Asbestoses and Othe Fibrous Minerals. J Natl Cancer I 67: 965-975.

8. Hinds WC (1999) Aerosol Technology: Properties, Behavior, and Measurement of Airborne Particles. (2ndedn), Wiley, New York.

9. Fujitani Y, Hirano S, Kobayashi S, Tanabe K, Suzuki A, et al. (2009) Characterization of Dilution Conditions for Diesel Nanoparticle Inhalation Studies. Inhal Toxicol 21: 200-209.

10. Fujitani Y, Saitoh K, Fushimi A, Takahashi K, Hasegawa S, et al. (2012) Effect of isothermal dilution on emission factors of organic carbon and $n$-alkanes in the particle and gas phases of diesel exhaust. Atmos Environ 59: 389-397.

11. Hasegawa S, Hirabayashi M, Kobayashi S, Moriguchi $Y$, Kondo $Y$, et al (2004) Size distribution and characterization of ultrafine particles in roadside atmosphere. J Environ Sci Health A Tox Hazard Subst Environ Eng 39: 2671 2690 .

12. Fushimi A, Hasegawa S, Takahashi K, Fujitani Y, Tanabe K, et al. (2008) Atmospheric fate of nuclei-mode particles estimated from the number concentrations and chemical composition of particles measured at roadside and background sites. Atmos Environ 42: 949-959.

13. Fujitani $Y$, Kumar P, Tamura K, Fushimi A, Hasegawa S, et al. (2012) Seasona differences of the atmospheric particle size distribution in a metropolitan area in Japan. Sci Total Environ 437: 339-347.

14. Fushimi A, Saitoh K, Fujitani Y, Hasegawa S, Takahashi K, et al. (2011) Organic-rich nanoparticles (diameter: $10-30 \mathrm{~nm}$ ) in diesel exhaust: Fuel and oil contribution based on chemical composition. Atmos Environ 45: 6326-6336.

15. Brasil AM, Farias TL, Carvalho MG (1999) A recipe for image characterization of fractal-like aggregates. J Aerosol Sci 30: 1379-1389.

16. Rogak SN, Flagan RC, Nguyen HV (1993) The Mobility and Structure of Aerosol Agglomerates. Aerosol Sci Technol 18: 25-47.
17. Park K, Kittelson DB, McMurry PH (2004) Structural properties of diesel exhaust particles measured by transmission electron microscopy (TEM): Relationships to particle mass and mobility. Aerosol Sci Technol 38: 881-889.

18. Okada K, Heintzenberg J (2003) Size distribution, state of mixture and morphology of urban aerosol particles at given electrical mobilities. J Aerosol Sci 34: 1539-1553

19. Barone TL, Zhu Y (2008) The morphology of ultrafine particles on and near major freeways. Atmos Environ 42: 6749-6758.

20. Mathis U, Kaegi R, Mohr M, Zenobi R (2004) TEM analysis of volatile nanoparticles from particle trap equipped diesel and direct-injection sparkignition vehicles. Atmos Environ 38: 4347-4355.

21. Kittelson DB, Watts WF, Johnson JP (2006) On-road and laboratory evaluation of combustion aerosols - Part 1: Summary of diesel engine results. J Aerosol Sci 37: 913-930.

22. Tumolva L, Park JY, Kim JS, Miller AL, Chow JC, et al. (2010) Morphologica and Elemental Classification of Freshly Emitted Soot Particles and Atmospheric Ultrafine Particles using the TEM/EDS. Aerosol Sci Technol 44: 202-215.

23. Wentzel M, Gorzawski H, Naumann KH, Saathoff H, Weinbruch S (2003) Transmission electron microscopical and aerosol dynamical characterization of soot aerosols. J Aerosol Sci 34: 1347-1370.

24. Maricq MM (2007) Chemical characterization of particulate emissions from diesel engines: A review. J Aerosol Sci 38: 1079-1118.

25. Keller A, Fierz M, Siegmann K, Siegmann HC, Filippov A (2001) Surface science with nanosized particles in a carrier gas. J Vac Sci Technol A 19: 1-8.

26. Oberdorster G (2000) Toxicology of ultrafine particles: in vivo studies Philosophical Transactions of the Royal Society of London Series a-Mathematical Physical and Engineering Sciences 358: 2719-2740.

27. Maier M, Hannebauer B, Holldorff H, Albers $P$ (2006) Does lung surfactant promote disaggregation of nanostructured titanium dioxide? J Occup Environ Med 48: 1314-1320. 